\title{
Simulation of the OECD/NEA Sandia Fuel Project Phases I\&II ignition tests with DRACCAR
}

Olivier de Luze, François Jacq, Gaetan Guillard.

HIGHLIGHTS

- An OECD/NEA PWR spent fuel pool experimental program is simulated with the code DRACCAR v2.3.

- New code modelings have been developed for radiative heat transfers in the bundle and for zirconium nitrides production.

- Air induced flow rates have been correctly reproduced in both storage patterns with the additional hypothesis of oxides swelling.

- Fuel clad temperature response for a recently discharged assembly in a uniform pattern is well assessed.

- Thermal response for bundles in a $1 \times 4$ pattern still depending on additional hypotheses not fully checked.

\section{ABSTRACT}

This paper provides a simulation of the two ignition tests performed at full power in the frame of the Sandia Fuel Project (SFP) with the thermo-mechanical code DRACCAR v2.3.

The OECD/NEA Sandia Fuel Project was built on an agreement between 12 countries from OECD, the Nuclear Energy Agency (NEA) and the US-NRC for the characterization of thermal-hydraulic and zirconium fire phenomena in pressurized-water reactor (PWR). The experimental program was split in two phases to focus at first on axial heating and burn propagation in one prototypic fuel assembly (Phase I), and then on axial and radial heating and burn propagation in $1 \times 4$ fuel assemblies (Phase II).

DRACCAR is a simulation tool, developed at IRSN, for fuel assembly mechanical behavior and coolability assessment during a LOCA transient. The flexibility of DRACCAR allows the modeling of many kinds of geometries. Because the code is based on a 3D non-structured meshing, it can be used to model any non-axisymmetric geometry, like the $1 \times 4$ fuel assemblies geometry of the Phase 2 of the SFP program.

In order to check the consistency of the modeling, we have optimized the code options to get best results for the Phase I, and applied the same options to the Phase II. A large part of the DRACCAR results have been very successful and challenging, leading to several code improvements and to specific hypotheses concerning the oxides formation. Air oxidation and breakaway modeling of the zircaloy claddings were successfully tested against the experimental results. Nevertheless parts of the experimental results of Phase II have been difficult to reproduce. As many causes could be involved in these difficulties, such as detailed evolution of the air convective loop, radiative heat transfers in the bundles, and the modeling of additional reactions of zirconium with nitrogen in places where oxygen is lacking, there is still room for improvement in the work of interpretation and modeling of the SFP tests.

Abbreviations: CA, Central Assembly; DRACCAR, Déformation et Renoyage d'un Assemblage de Crayons Combustibles pendant un Accident de Refroidissement; FR, Flow Rate; HT, Heat Transfer ; IRSN, Institut de Radioprotection et de Sûreté Nucléaire ; KIT, Karlsruhe Institute of Technology; LOCA, Loss Of Coolant Accident ; US-NRC, US Nuclear Regulatory Commission; PA, Peripheral Assembly; PBR, Pilling and Bedworth Ratio; SFP, Sandia Fuel Project, Spent Fuel Pool. 


\section{Introduction}

Prior to 2001, the US-NRC performed an evaluation of the potential accident risk in a spent fuel pool (SFP) at decommissioning plants in the United States (Collins 2001). Some of the assumptions in this evaluation were known to be conservative. SFP accident research was carried out with computer codes to predict the severe accident progression following various postulated accident initiators. Various modeling and phenomenological uncertainties prompted a need for experimental confirmation.

From 2003 to 2012, the US-NRC undertook an experimental program to address thermal-hydraulic conditions and zirconium fire propagation during a complete loss of coolant accident in a boiling-water reactor (BWR) spent fuel pool (Lindgren 2013a, b). In that program, two kinds of tests series were performed. A first test series was performed with a single, full-length highly prototypic fuel assembly inside a prototypical pool rack cell, corresponding to a uniform SFP pattern of recently discharged, highpowered assembly (Fig. 1). It was followed by a second test series corresponding to five short assemblies (1/3 length) contained in a $3 \times 3$ pool rack and corresponding to a $1 \times 4$ loading pattern.

These experiments demonstrated that BWR fuel assemblies can lead to ignition which further propagates axially and radially in the pool rack during a complete loss of coolant accident.

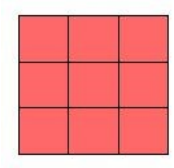

Uniform Pattern

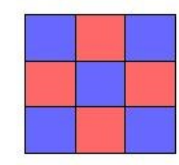

Checkerboard Pattern

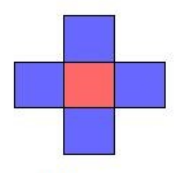

$1 \times 4$ Pattern
Recently discharged, high-powered assembly

Low-powered assembly discharged many years earlier

Fig. 1 loading patterns (NUREG 7143)

In the meantime, code calculations for pressurizedwater reactor (PWR) assemblies were also performed, leading to ignition prediction and complete fuel degradation for assemblies. However, experimental and qualified data obtained in representative fuel configurations were needed to confirm these results. In May 2009, 12 countries from OECD, the Nuclear Energy Agency (NEA), and the USNRC signed an agreement to perform experiments focused on thermal-hydraulic and zirconium fire phenomena in a PWR spent fuel pool. This program lasted from 2009 to 2013. Similarly to the previous BWR study, the Sandia
Fuel Project was split in two parts in order to first study the zirconium fire propagation in one assembly alone, and then to look out for the propagation of the fire from the central assembly to the neighboring assemblies, simulating a $1 \times 4$ loading pattern. The SFP series used full-length commercial fuel assemblies' mockup. A benchmark was asked to the partners after each ignition test, for code comparison and improvement. The results of the first benchmark have been published (Adorni 2016) leading to similar results among the partners, insofar as hydraulics has been properly described due to the availability of accurate hydraulics data in the test series.

As an OECD partner, IRSN participated only to the Phase II of that program using the ASTEC (Chatelard 2016) and DRACCAR (Glantz 2017) codes. The main physical effects were related to thermal hydraulics, cladding oxidation kinetics and heat exchange within cells, and between adjacent cells, in a non-axisymmetric geometry. The argument of non-axi-symmetry was decisive for running mainly the DRACCAR code in the post-test recalculations and not ASTEC.

DRACCAR is a multi-physics code for computational analysis of multi-rod ballooning and fuel relocation during LOCA transients. The main features of rod ballooning and fuel relocation of the code have not been used, but we have taken advantage of the unstructured meshing capability of the code to reproduce the exact geometry of the $1 \times 4$ loading pattern cells assemblies.

This paper will deal with DRACCAR calculations for both test series. A best data set will be worked out for the Phase-I, and applied for the Phase-II calculations, thus illustrating the good consistency within the code modeling to calculate two different sets of geometries with the same code options.

The simulation of the whole accident sequence was challenging, leading to several code improvements and to a better understanding of the whole experimental sequence.

\section{Sandia Fuel Project}

\subsection{OCDE/SFP Experimental program}

The program was conducted in two phases. The Phase I (Durbin 2016a) focused only on axial heating and burn propagation, while the Phase II (Durbin 2016b) addressed both axial and radial heating and burn propagation, including effects of fuel rod ballooning. Each part of the program included many tests: from unheated flow tests, to preignition tests, and to a final destructive ignition test. In this paper, we will focus only on the final destructive part of each test. 
The test assemblies were fully instrumented to get measurements of the inlet flow rates, of the thermal responses of the rods throughout the assembly, and of the amounts of nitrogen, oxygen, and argon in the exhaust stream directly above the test bundle.

Phase-I looked at a single PWR fuel assembly within a storage cell at commercially available sizes. The single test assembly was completely insulated to model boundary conditions representing a "hot neighbor" loading pattern ("Uniform pattern" Fig. 1), which is a typical bounding scenario. The heated fuel rods were filled with compacted magnesium oxide $(\mathrm{MgO})$ powder, with a thermal mass $(\rho \mathrm{Cp})$ similar to that of uranium dioxide $\left(\mathrm{UO}_{2}\right)$, making $\mathrm{MgO}$ powder an excellent surrogate for spent fuel. This phase gave experimental insights for ignition timing and burn propagation in a single $17 \times 17$ PWR assembly.

Phase-II was composed of five full-length assemblies placed in a $3 \times 3$ pool rack, with the central cell being the only heated assembly. These boundary conditions experimentally represent a "cold neighbor" situation (" $1 \times 4$ pattern" Fig. 1), that completes the bounding scenario covered by Phase-I. All mockup fuel assemblies were constructed with zirconium alloy cladding and prototypic structural components.

The central assembly used the same heated design as the one used in Phase-I. The unheated peripheral fuel rods were filled with high-density $\mathrm{MgO}$ ceramic pellets sized to precisely match the thermal mass of real spent fuel rods. Two of the four peripheral assemblies were pressurized with argon gas (at different pressures) so that these fuel rods would balloon when the zirconium-alloy cladding reached a high enough temperature. The two peripheral assemblies without pressurized rods were used to compare and evaluate the effects of ballooning.

\subsection{Main test outcomes}

\subsubsection{SFP Phase I results}

The final ignition test was conducted in March 2011 at a simulated decay power of $5.0 \mathrm{~kW}$, equivalent to an offload duration of approximately 17 months. The first detection of the ignition temperature $(1200 \mathrm{~K})$ of the Zircaloy claddings within the assembly happened at 12.66 hours after the test onset, near the top of the rods at $3.302 \mathrm{~m}$. The test assembly continued to react for several days after the first ignition, leading to the final destruction of the assembly due to the very high temperature level being reached.

At these high temperatures, zirconium readily reacts with oxygen to form a zirconium dioxide product layer, with a highly exothermic reaction. During the burn phase, the oxygen concentration dropped to zero due to the zirconium oxidation reaction, converting $14 \%$ of the initial bare zirconium to $\mathrm{ZrO}_{2}$.

Additional mechanisms come into play when nitrogen is present in the gas phase. The nitrogen reacts with zirconium to produce $\mathrm{ZrN}$ in a spot wise manner. According to the exhaust gas analysis, about $20 \%$ to $40 \%$ of the zirconium in the assembly was converted to $\mathrm{ZrN}$. These results indicate that the hot oxygen starved environment remaining after the passage of the burn front is ideal for significant zirconium nitride formation.

\subsubsection{SFP Phase II results}

The final ignition test was conducted in June 2012 at a simulated decay power of $15.0 \mathrm{~kW}$ for the central assembly, representing a three-month-offload assembly (at 45 GWd/MTHM burnup).

The first ignition temperature of the Zircaloy claddings was observed after 6.31 hours in the central fuel assembly, at a similar level than for the Phase-I test (at $3.302 \mathrm{~m}$ ). The cladding fire propagated transversely into the peripheral assemblies at 7.08 hours and $3.150 \mathrm{~m}$. The progression of the ignition front across the entire cross section of all of the peripheral assemblies was detected at 8.74 hours. The thermal-hydraulic behavior of assemblies with ballooned rods did not appear to be much different from the unpressurized assemblies. So, in the following calculations, we will not consider any cladding deformation modeling.

The gases measured at the exhaust were composed of nitrogen, oxygen, argon, water, carbon dioxide, and helium. Argon and helium, as inert gases, have been used as a measuring technique of the removal and the release of the reactive gases. Argon was also the filling gas of the pressurized rods and can be used for the detection of the failed rods. The analysis shows two distinct stages of oxidation:

-i) a first and very energetic oxidation stage remained for eleven hours after ignition. During that stage all the oxygen entering the assembly was consumed by the zirconium oxidation, as well as a substantial portion of the nitrogen which was consumed by production of the nitride from much (if not most) of the remaining unoxidized zirconium. This stage corresponds roughly to the phase of the downward movement of the ignition front, with a hot oxygen starved zone above the front.

-ii) a second oxidation stage continued for eightyheight hours after the first one. During that period, all of the oxygen entering the assembly was consumed by the oxidation of the remaining intact zirconium as well as by the oxidation of the zirconium nitride, as indicated by the release of nitrogen gas. 
All five fuel assemblies were completely consumed at the end, as a result of the propagation of the zircaloy cladding fire.

\subsection{Phenomenological approach}

In these integral tests, we are faced with three kinds of physics, which are strongly interconnected: additional heat due to complex chemistry, specific hydraulics of full-length assemblies, convection and radiation heat exchanges mechanisms within and between assemblies.

If post-test recalculations are restricted to the description of the total flow rates and to the timing of the first ignition event in the central cell, it's really doable. But the calculations of both SFP integral tests could be truly a challenge to recalculate if we look into experimental details, because the modeling of physics which is needed is sometimes at the brink of the models used in the code.

We are faced with $17 \times 17-25$ electrically heated rods at commercial size whose power is then managed (above $1440 \mathrm{~K}$ ) by complex chemical reactions, much dependent on local flowrates and air composition.

There are asymmetrical heating conditions of the cells which must be taken into account, at least by the geometry modeling, but also in considering that cross flows and convective loops within the bundles have to be taken into account, as well as the grid effects. Even with a correct recalculation of the total inlet flow rates, the exact flow distribution within the bundle is not well known, especially for the peripheral non-heated cells, with probable effects on thermal evolution. The partitioning of the flow between the bundle and the annular regions has been studied in the preignition tests (Lindgren 2016b) showing a strong dependence on storage cell size, with values of the flow in the annular space ranging from $35 \%$ to $50 \%$ of the total flow. A larger flow close to the cell wall could modify the thermal evolution of the wall, the gradient of temperature within the bundle, as well as the timing of ignition.

Cladding oxidation by air induces a more exothermic reaction than in steam, leading to a very high temperature increase of the cladding in the oxidation zone. Above ignition temperatures, radiation is the main heat transfer mechanism. The generally accepted assumption is that axial radiative flux can be neglected. However, in the code modeling, the chemical additional heating leads to in a very strong axial temperature gradient of more than $100^{\circ} \mathrm{C} / \mathrm{cm}$, for which the axial radiative flux should be considered.

\section{Post-test calculations results with the DRACCAR code}

\subsection{The DRACCAR code}

DRACCAR is a simulation tool for fuel assembly mechanical behavior and coolability assessment during a LOCA transient. Its aim is to simulate the $3 \mathrm{D}$ thermomechanical deformation and reflooding of a fuel rod assembly including its coolability as well as structure embrittlement (Glantz 2017). The flexibility of the DRACCAR code allows to model from a simple fuel rod up to a full core, with surrounding shrouds. The code uses a 3D nonstructured meshing: the horizontal discretization defines sub-channel thermal-hydraulics while the axial discretization leads to analyze quasi-independent 2D thermal- mechanical problems.

It is currently coupled to the two phase flow module CESAR of the ASTEC code (Trégourès 2010). The combination of DRACCAR and CESAR codes enable the modelling of various phenomena including heat transfer (HT) within solids and HT to the fluid, material property evolution (growth of an oxidic layer, phase change), contact between structures and cladding integrity (Bascou 2015). To allow the simulation of spent fuel pool draining accidents, some models have been developed (or improved) and main concerns are air oxidation and nitriding, as well as axial radiative HT (to account for very high axial temperature gradients).

\subsection{SFP-Phase I post-test calculations}

Post-test calculations start with a calculation made using the most standard code options and taking into account the experimental conditions. Then, a set of parametric calculations are made to improve code results, ending with a best estimate calculation. The main significant hypotheses to reach the best estimate calculation are detailed in the following sections.

\subsubsection{General simulation setup}

In order to model any geometry with DRACCAR, one has to first create the nodes which then will define the meshing; the rods being placed either on the nodes or within the mesh structure. For the modeling of the Phase I, eight meshes have been defined to describe the bundle in its width, leading to 64 meshes for the whole bundle. Within these meshes, 264 heated rods and 25 guide tubes have been modeled with weighed representative elements. Due to symmetry considerations, only $1 / 8$ th of the bundle has been modeled for faster calculations, and $1 / 8$ th of the weighed rods (full circles) and of the guide tubes (hollow circles) have been distributed within 10 hydraulic channels 
(Fig. 2r). The bundle is placed into a stainless steel pool rack cell of $1.91 \mathrm{~mm}$ thickness, wrapped into an insulation layer of $15.24 \mathrm{~cm}$ thick, made of kaowool.

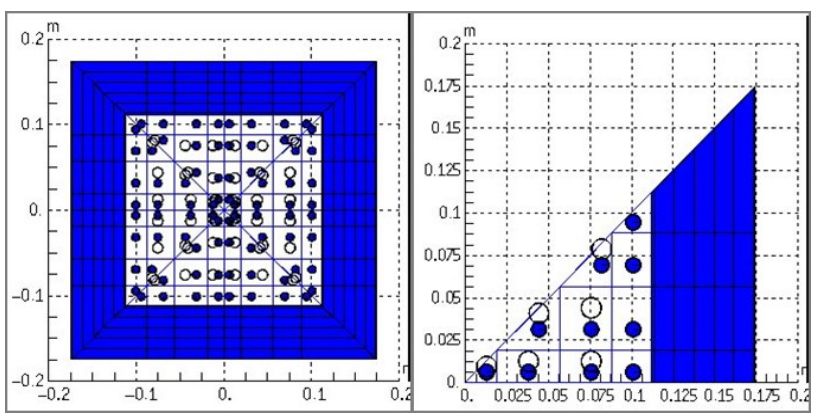

Fig. 2 SFP-I meshing left: whole bundle meshing, right: $1 / 8$ modeled

Each rod is made of compacted magnesium oxide powder $(\mathrm{MgO})$ held inside a Zircaloy cladding. According to the test specifications (Durbin 2016b), the heated length of the rods is similar to the PWR heated layout $(3.613 \mathrm{~m}$ height) and the heating power is generated in the $\mathrm{MgO}$ powder. This power is stopped as soon as a temperature of $1440 \mathrm{~K}$ has been reached in the bundle, to avoid experimentally any short-circuit in the facility. This indicates that all the degradation phase of the test is due to the sustained claddings oxidation reactions in the bundle. The meshing height in the heated rod length is $10 \mathrm{~cm} / \mathrm{mesh}$. This height is a good compromise to get both accurate code results and short timings for the various parametric calculations.

Table 1 Fuel model parameters.

\begin{tabular}{ll}
\hline Description & \\
\hline Number of fuel rods per assembly & 264 \\
Number of control rods guide tube per assembly & 25 \\
Fuel filler material & $\mathrm{MgO}$ \\
Fuel and tube cladding material & $\mathrm{Zirc}$ \\
Heated fuel axial length (mm) & 3613 \\
Fuel rods and tube axial length (mm) & 3942 \\
Storage cell inner diameter (mm) (SFP-I) & 223.4 \\
Central cell inner diameter (mm) ) (SFP-II) & 224.2 \\
Peripheral cell inner diameter (mm) ) (SFP-II) & 222.6 \\
\hline
\end{tabular}

Additional information is presented in Table 1. All the physical properties of the $\mathrm{MgO}$ powder and the kaowool material have been taken from the Sandia report on MELCOR calculations (Cardoni 2010).

\subsubsection{Hydraulics}

Prior to the final ignition experiment, several separate effect tests were performed to investigate the hydraulic response of the assembly, and to estimate the flow resistance coefficients $\left(\mathrm{S}_{\mathrm{LAM}}\right.$ and $\left.\sum \mathrm{k}\right)$ for input data to the US-NRC severe accident code MELCOR. The measured friction loss coefficients were significantly different (and larger) from generally accepted values. The usual value of the $\mathrm{S}_{\mathrm{LAM}}$ coefficient for a bundle flow is 100 (from textbooks), and the measured values range from 164 (for a Cell Internal dimension (ID) of $217.5 \mathrm{~mm}$ ) to 129 (for Cell ID of $223.4 \mathrm{~mm}$ ) (SFP-Phase-I Ignition Cell) (Lindgren 2013b). The form loss coefficients didn't depend much on the Cell ID.

Pre-ignition DP adjustments: to adjust the DRACCAR data set to the pre-ignition part of the test, we have only modified the singular pressure loss coefficient "kin" in order to find the experimental induced flow rate. The friction loss coefficients were left unchanged. As the value of the pressure losses both at the top nozzle and at the bottom one are unknown, we defined only one total form loss at a given elevation ' $z$ ', instead of modeling the several spacer grids. The value 'kin' of the pressure loss is adjusted to reach (in the calculations) the correct maximum flow rate (FR) at $\sim 2 \mathrm{~h}$ (Fig. 3).

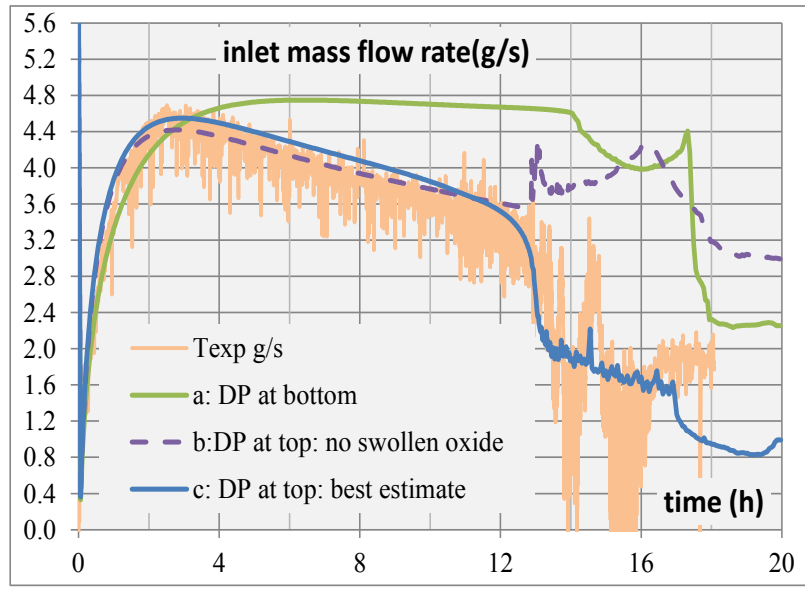

Fig. 3 SFP-I exp. FR: temperature effect

According to DRACCAR calculations, the following smooth decrease of the FR after two hours is mainly due to the increase of the form loss pressure drop with the temperature. This is illustrated in Fig. 3 in which the experimental mass flow rate is compared to the calculated ones, with "kin" defined at different heights. The ' $a$ ' curve results from "kin" defined at the bottom of the bundle, and the curves ( $b$ and c) with "kin" defined near the top of the rods. For the ' $a$ ' plot, as the temperature remains roughly constant at that level, the pressure drop remains constant, leading to a rather constant mass FR once the maximum value has been reached. For the (b, c) plots, the increase of temperature near the top leads to an increase of the pressure drop of about three times the bottom value, thus leading to 
a smooth decrease of the mass FR, very similar to the experimental one.

Post-ignition adjustments: defining the 'kin' coefficient in the upper bundle part (Fig. 3 plot b), there is only a smooth increase of the mass FR once reaching the ignition conditions. This effect is similar to some "chimney effect" caused by the increase of the oxidation reactions of the cladding in the bundle. This goes opposite to the experimental sharp decrease of the flow at that moment, as if some channel blockage happened somewhere. But a general twist of the bundle is not expected to reduce the channel cross-section at these temperature levels $\left(900^{\circ} \mathrm{C}-1400^{\circ} \mathrm{C}\right)$.

So, in order to reproduce this experimental evidence, we used the working hypothesis that the channel reduction came from the formation and the growth of a highly porous zirconia layer during air ingress conditions. The layer being built upon the oxidation of $\mathrm{ZrN}$ compounds, the following volume increase could be reached in the calculations.

Porous zirconia layer: the hypothesis of a porous zirconia layer is based on a model of zircaloy oxidation in air proposed by M. Lasserre (Lasserre 2015).

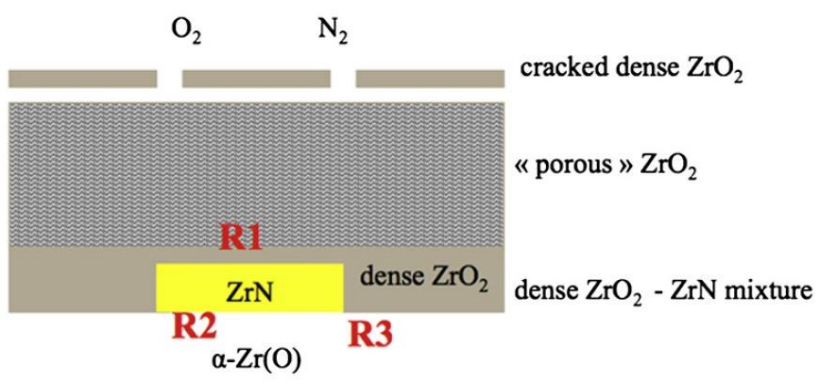

Fig. 4 Scheme in the reaction zones (Lasserre)

In that model, starting from a cracked (initially dense) zirconia layer permeable to gases, a porous zirconia layer (containing both dense zirconia and $\mathrm{ZrN}$ precipitates) is formed (Fig. 4) with the following reactions to describe the advance of the oxide/metal interface, taking place near the interface:

$$
\begin{aligned}
& \mathrm{ZrN}+\mathrm{O}_{2}=\mathrm{N}^{*}+\mathrm{ZrO}_{2} \\
& \mathrm{~N}^{*}+\mathrm{ZrOx}=\mathrm{ZrN}+\mathrm{xO}^{*} \\
& (2-\mathrm{x}) \mathrm{O}^{*}+\mathrm{ZrOx}=\mathrm{ZrO}_{2}
\end{aligned}
$$

Where $\mathrm{ZrOx}$ is used for the $\alpha-\mathrm{Zr}(\mathrm{O})$ phase.

According to Lasserre, oxidation and nitriding reactions are at the origin of the porosity observed in the posttransition oxide layer, and $\mathrm{ZrN}$ can be seen as a catalyst for zirconium oxidation.
The increase of the porous zirconia layer thickness is linked to the volume increase of the previous reactions scheme: the nitridation of $\alpha-\operatorname{Zr}(\mathrm{O})$ occurs without volume change and leads to a two phase $\mathrm{ZrN} / \mathrm{ZrOx}$ layer (R2). The oxidation of the $\alpha-\operatorname{Zr}(\mathrm{O})$ phase leads to a volume increase (the Pilling and Bedworth ratio $\mathrm{PBR}_{\mathrm{ZrO} / \mathrm{Zr}}$ is 1.56 ) which induces cracks (R3). The $\mathrm{ZrN}$ precipitates are finally oxidized leading to another volume increase $\left(\mathrm{PBR}_{\mathrm{ZrO} / \mathrm{ZrN}}\right.$ is 1.47).

Data set modifications: those detailed chemical reactions are not modeled in the code, but in order to increase the volume of the oxides formed during the oxidation phase, we have reduced the oxides density by a factor three, in agreement with the previous analysis. These densities are gathered in the Material Data Bank (MDB) in which all the material and fluid properties are defined for both the DRACCAR and CESAR codes. The factor three will lead to volume increases close to the value of the cumulated volume increases due to R1 and R3 reactions. The corresponding code results (Fig. 3 plot c) are very close to the experimental ones, showing a sharp decrease of the mass $\mathrm{FR}$ at the beginning of the ignition stage.

This volume increase induces an additional mesh blockage in the calculation, illustrated in Fig. 5 when the ignition front is close to $2 \mathrm{~m}$. In that figure we have plotted the blockage fraction of the rods in a mesh, for the ten hydraulic channels modeled. For the internal channels, there is an initial blockage of about $50 \%$ before any oxidation of the rods (bottom), increasing to $\sim 65-70 \%$ after the oxidation of the cladding. These results indicate that in order to reproduce a correct reduction of the mass FR due to oxidation, we have to simulate an increase of mesh blockage due to porous oxide formation of about $30-40 \%$.

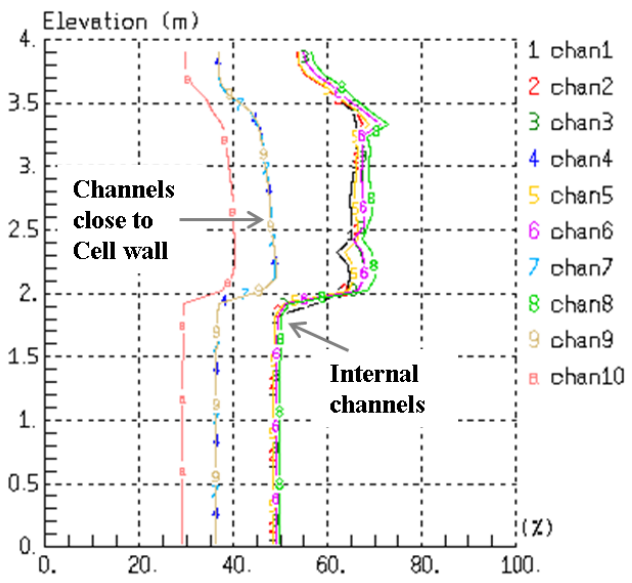

Fig. 5 Mesh blockage induced by oxide volume increase

Remark: the previous modeling, which describes the advance of the porous zirconia layer, is based on the existence of an initial $\mathrm{ZrN}$ precipitate which can be formed prior the 
experimental detection of the global oxygen starvation zone. According to Duriez and Steinbrück (Duriez 2008, Steinbrück 2009) local oxygen starvation consecutive to the appearance of cracks in the pre-transition zirconia layer can favour the formation of the $\mathrm{ZrN}$ compound at the bottom of cracks.

\subsubsection{Axial radiative heat transfers between meshes}

With code options leading to a correct mass FR, and using the standard modeling concerning the three kinds of heat transfer mechanisms (conduction, convection, radiation), code results led to very high temperatures in the bundle $\left(\sim 2000^{\circ} \mathrm{C}\right)$ after the first ignition, due to the runaway of the cladding oxidation reactions in the bundle (Fig. 7). Unfortunately, maximum temperatures reached in the bundle are not known exactly due to the failure of the thermocouples above $1200^{\circ} \mathrm{C}$. Looking at the whole set of experimental temperatures, rod temperatures in the range 1300$1400^{\circ} \mathrm{C}$ are more expected in the downward progression of the front, but without experimental evidences.

The progression of the ignition front is however available from the experimental results, with a velocity close to $\sim 1 \mathrm{~m} / \mathrm{h}$ in the half-upper part of the bundle, compared to 0.3 $\mathrm{m} / \mathrm{h}$ in the calculations (Fig. 7). This low value of the calculated velocity is related to the high temperatures reached in the calculation, and a consequence to the formation of a large temperature difference between axial meshes, as illustrated in Fig. 8. In that figure axial temperature profiles have been plotted at the occurrence of the first ignition event (a) and after a time delay of $2.4 \mathrm{~h}$ (b). At that time, the maximum axial temperature gradients are about $100^{\circ} \mathrm{C} / \mathrm{cm}$ (which gives a temperature differences of $1000^{\circ} \mathrm{C}$ between adjacent meshes at peak temperatures), and the calculated ignition front is at $2.7 \mathrm{~m}$, while in the test it is already at $1.4 \mathrm{~m}$.

For temperatures above the ignition temperature, the main contribution for the HT mechanisms is radiation, and in the usual code modeling, the axial radiative flux is often neglected for two main reasons (Glantz 2017):

- the use of a rather coarse axial meshing pointing out a small ratio of the fluid cross section over the vertical structure surface. The view factor of a vertical structure in the horizontal slice if much larger than its view factors upward and downward, especially because structures are close together,

- a smooth axial temperature gradient.

But if the axial discretization is quite fine (typically close to the hydraulic diameter), and if the temperature gradient is sharp, then the axial radiative heat transfer can become significant and even prominent. In the DRACCAR scope, this situation is only met during the late phase of the spent fuel pool uncovery when the assemblies are oxidized by air. In order to well reproduce these situations, a rather simple radiative axial model has been chosen. It is based on an axial conduction evaluating coarsely the axial radiative heat flux. The main assumptions are:

- in a fluid channel, the difference of temperatures between two wet structures in two neighboring axial fluid meshes is greater than the difference of two wet structures belonging to the same fluid mesh,

- the heat transfer is performed locally, to the meshes just above and just below, without trying to propagate the radiative flux to the next meshes.

The first assumption is used to simplify strongly the heat transfer: instead of computing a heat transfer for all the possible couple of wet structures (one in each considered neighboring meshes), a wet structure mesh will exchange energy only with the wet structure meshes just above and just below which belong to the same structure (Fig. 6). That assumption is valid if the equivalent weighted rod represents an enough great number of rods.

In order to manage these corrective effects, a code input coefficient has been defined to apply all -or part- of theses heat exchanges corrections (from $0 \%$ to $100 \%$ ).

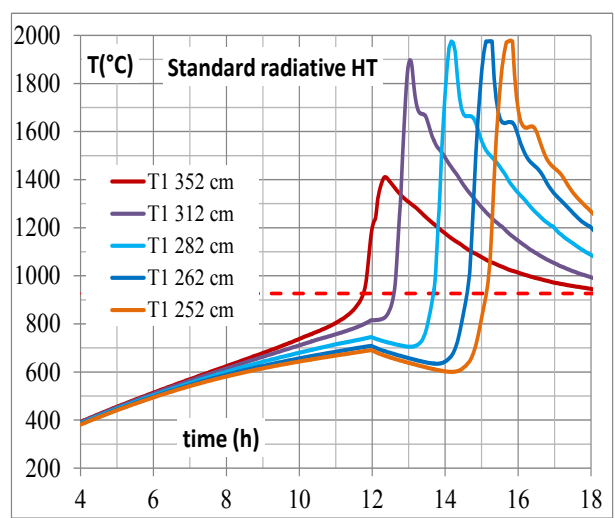

Fig. 7 Rod temperature at ignition level

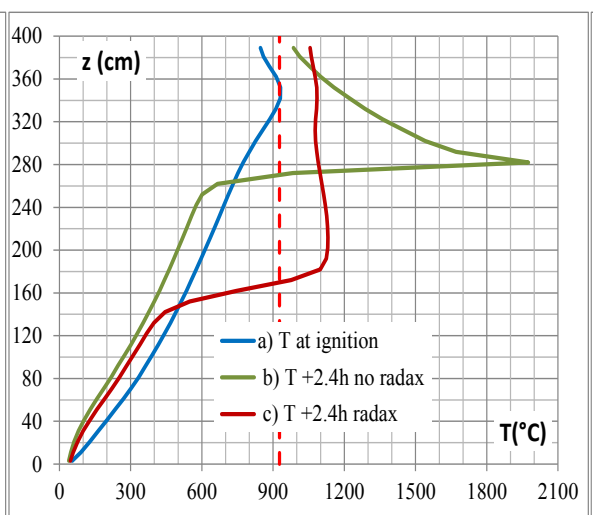

Fig. 8 Central rod temperature profile

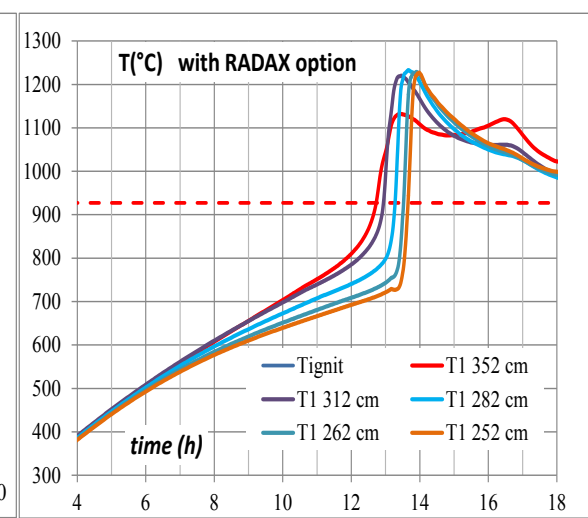

Fig. 9 Rod temperature at ignition level 


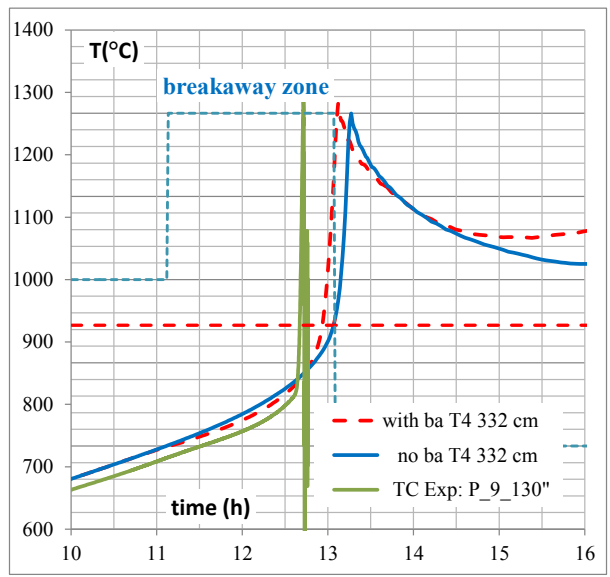

Fig. 10 Breakaway effect at ignition

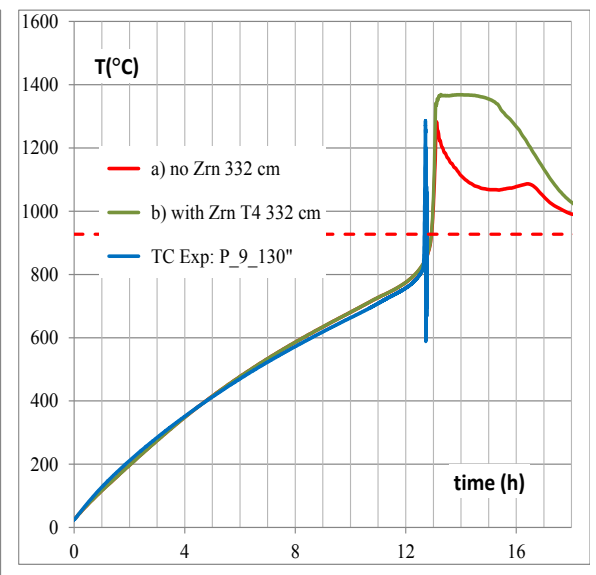

Fig. 11 Temperature evolution at $330 \mathrm{~cm}$

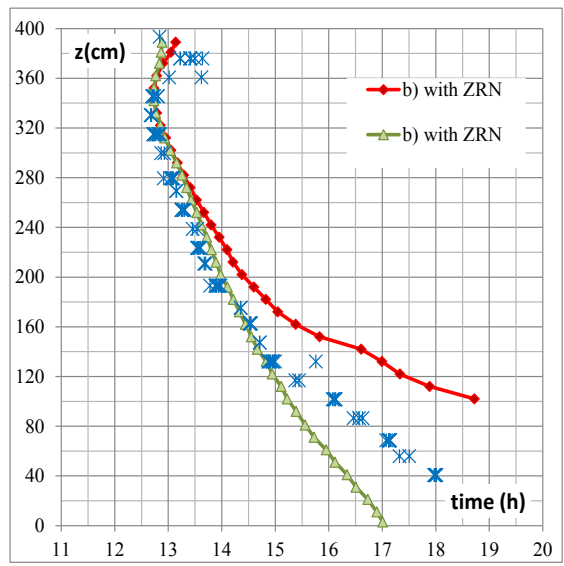

Fig. 12 Evolution of the ignition front
Code results using $75 \%$ of these axial radiative transfers are given in Fig. 8c and Fig. 9. Maximum temperatures remain below $1300^{\circ} \mathrm{C}$ and axial temperature gradients stay under $30^{\circ} \mathrm{C} / \mathrm{cm}$. The axial propagation of the ignition front is faster $(\sim 1 \mathrm{~m} / \mathrm{h})$, and very close to the experimental one.

The main effect of the axial radiative HT model is to reduce the temperature rates and to flatten the axial temperature profile, and the consequence is a de-coupling of the temperature runaway between the center rods and the outer ones.

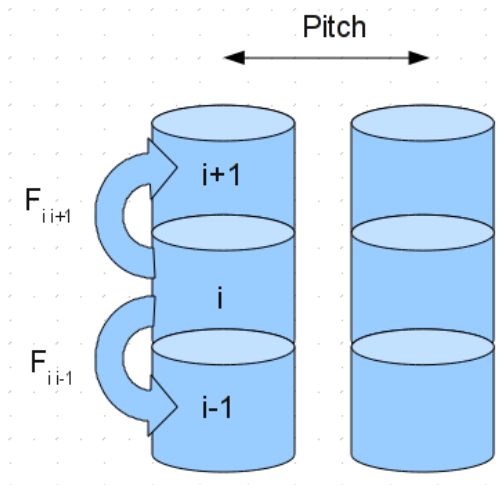

Fig. 6 Axial radiative HT hypothesis

\subsubsection{Cladding oxidation model}

During the ignition phase, the temperature rates increase strongly as a result of cladding oxidation with air. Since oxidation reactions are strongly exothermal, they result in a self-sustained zirconium fire, leading to structural degradation of the fuel assembly and to the release of fission products. The onset of these processes is much de- pendent on the kinetics of the zirconium-air reactions used in the code.

The DRACCAR V2.3 model of Zircaloy oxidation by air comes from a model originally developed for the ICARE/CATHARE V2 mechanistic code (Coindreau 2010). In the low temperature range (up to $110{ }^{\circ} \mathrm{C}$ ), the interaction between $\mathrm{Zr}$ and $\mathrm{O}_{2}$ follows a parabolic kinetics. Then, partly due to the presence of nitrogen, the initially dense and protective oxide layer starts to crack, leading to a transition in the kinetics law (breakaway): the oxidation is no more controlled by the diffusion of oxygen through the oxide layer, and the acceleration of the oxidation kinetics is taken into account according to the IRSN MOZART experimental data (Duriez 2008).

This accelerated kinetics does not last long. The subsequent transition to the post-breakaway regime is based on reaching a critical value of the oxygen mass gain, depending on the temperature level. The post-breakaway regime is modelled by a linear law. Above $1200^{\circ} \mathrm{C}$, independently of the value of the oxygen mass gain, there is no more breakaway regime.

DRACCAR calculations show that the modeling of the breakaway has only a small effect on the timing of the first ignition and on the following temperature evolutions. This is mainly because of the low value of the external thermal losses which lead to high temperature rates and small time delay between the kinetics transition $\left(730^{\circ} \mathrm{C}\right.$ in Fig. 10) and the beginning of the runaway temperature effect. A calculation not using the breakaway modeling delays the first ignition event by only seven minutes. This is not much significant. 


\subsubsection{Best estimate results}

The main results to be checked are related to thermal results (first occurrence of ignition in the bundle, and the following evolution of the ignition front), and to the oxidation of the claddings in terms of amounts of initial zirconium converted.

Thermal results: taking into account all the previous modifications, the code results have been plotted in Fig. 11 and (Fig. 12, plot a). The temperature evolution at the first ignition level $(3.3 \mathrm{~m})$ is very close to the experimental one. The ignition time is calculated at $12.73 \mathrm{~h}$, as compared to $12.66 \mathrm{~h}$ in the test. The axial propagation of the front is correct at the beginning, but becomes slower than the experimental one below $2 \mathrm{~m}$, even with the axial radiative HT option which increases the downward front velocity. At 1.2 $\mathrm{m}$, the calculated ignition front shows a delay of about $2 \mathrm{~h}$ compared to the experiment.

Remark: code results used $75 \%$ of the axial radiative transfers. Calculations done using a correction of $100 \%$ did not change the late propagation of the ignition front. The axial radiative HT modeling can no longer be used to improve code results at that level.

Claddings oxidation: during the burn phase, according to the experimental report (Durbin 2016a), all of the oxygen was removed from the air drawn into the assembly, thus converting:

i) $14 \%$ of the initial zirconium to $\mathrm{ZrO}_{2}$,

ii) and (20\% to $40 \%)$ of the initial zirconium to $\mathrm{ZrN}$,

and letting all the volume above the front free from oxygen (starvation conditions).

The first part of these experimental evidences can be easily checked in the code. The amount of initial zirconium converted into oxide $\left(\alpha-\mathrm{Zr}(\mathrm{O})\right.$ and $\left.\mathrm{ZrO}_{2}\right)$, when the front reaches the level at $3 \mathrm{~m}$, is $33 \%$ for all the weighed rods in the ten hydraulic channels. As there is an equal formation of $\alpha-\mathrm{Zr}(\mathrm{O})$ or $\mathrm{ZrO}_{2}$, we have about $16 \%$ of initial $\mathrm{Zr}$ converted in $\mathrm{ZrO}_{2}$, much like in the experiment. These results validate the oxidation modeling used in the code.

Remark: going into details, there is more oxidation for the four rods close to the Cell with $50 \%$ of initial $\mathrm{Zr}$ converted in $\mathrm{ZrO}_{2}$ and less oxidation for the six internal rods, with only $23 \%$ of initial $\mathrm{Zr}$ converted in $\mathrm{ZrO}_{2}$.

The second part is linked to experimental evidence of nitriding reactions during the test. The effect of Nitrogen on the kinetics has been already taken into account in the breakaway modeling during the oxidation, but not in considering a specific kinetics for the formation of zirconium nitrides. In using such a model, we could expect that the additional heat source from these new reactions could sustain the ignition front and increase its downward velocity below the mid-plan bundle.

Zircaloy nitriding modeling: in order to account for nitrides formation, the detailed chemical reactions given previously (\$3.2.2) were not considered at all, but rather a model was built based on a kinetics law and on threshold parametric coefficients for gas partial pressures. The main hypotheses are the following:

- Nitriding reactions happen only under starved oxygen conditions. This assumption is coherent with the fact that $\mathrm{ZrN}$ is only stable at very low oxygen partial pressure (below $10^{-22} \mathrm{~Pa}$ ), at $1200 \mathrm{~K}$, and for nitrogen partial pressure around $10^{5} \mathrm{~Pa}$ (Steinbrück 2014). In the code, it is modeled by a minimum oxygen pressure to be fulfilled to start reactions.

- The chemical reaction is between oxygen-stabilized $\alpha-\operatorname{Zr}(\mathrm{O})$ and nitrogen:

$$
\mathrm{ZrO}_{0.25}+0.5 \mathrm{~N}_{2} \rightarrow \mathrm{NZrO}_{0.25} \quad(\Delta \mathrm{H}=-370 \mathrm{~kJ} / \mathrm{mol})
$$

The mass gain for this reaction follows a linear kinetics according to the formula: $\Delta \mathrm{m} / \mathrm{S}=\mathrm{K}$.t, where $\Delta \mathrm{m}$ the mass gain, $\mathrm{S}$ the sample surface, and $\mathrm{K}$ the rate constant which follows an Arrhenius law. This rate constant $\mathrm{K}$ has been determined accordingly to the experimental results given by KIT (Steinbrück 2014) and illustrated in Fig. 13.

Experimental results show that the rate constant $\mathrm{K}$ increases up to $1200^{\circ} \mathrm{C}$ and decreases sharply to very a low value at $1400^{\circ} \mathrm{C}$ (null value in the modeling). Because of the additional constraint of starved oxygen, existing roughly above $1000^{\circ} \mathrm{C}$, this indicates that there is a $\sim 300^{\circ} \mathrm{C}$ temperature window $\left(1000^{\circ} \mathrm{C}\right.$ to $\left.1300^{\circ} \mathrm{C}\right)$ in which nitriding reactions can happen and sustain oxidation reactions.

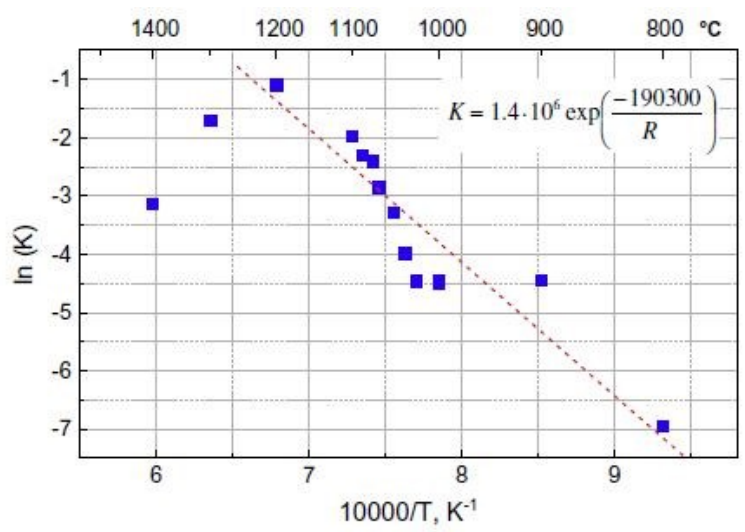

Fig. 13 Linear rate constant of nitriding of $\alpha-\operatorname{Zr}(\mathrm{O})$ (Steinbrück) 
This is a very basic model regarding to experimental results, in which the mass gain of nitrided samples increases with the temperature and with the oxygen content of $\alpha$ $\mathrm{Zr}(\mathrm{O})$. We used the kinetics based on claddings with $6.5 \mathrm{wt} \%$ oxygen content, which is the strongest kinetics, and which is considered as envelope kinetics.

Code results using the nitriding model are given in Fig. $11 \mathrm{~b}$ and Fig. 12b. The time for the first ignition remains unchanged because it is mainly triggered by the oxidation reactions. The temperature rates at ignition are slightly increased from $50^{\circ} \mathrm{C} / \mathrm{min}$ to $80^{\circ} \mathrm{C} / \mathrm{min}$, still lower than the experimental ones $\left(170{ }^{\circ} \mathrm{C} / \mathrm{min}\right)$.

The two main changes related to this modeling are the value of the maximum temperature which remains close to $1400^{\circ} \mathrm{C}$ during two hours (this value is closely related to the nitriding kinetics which stops above $1400^{\circ} \mathrm{C}$ ) and the evolution of the ignition front which is now closer to the experimental values, at least for elevations above $1 \mathrm{~m}$. Below this level, the faster progression of the calculated front is certainly due to the calculated mass flow rate which is larger than the exp. one (Fig. 3) due to some experimental blockages that are not modeled here.

\subsubsection{Summary of the Phase-I calculations}

Best calculations of the SFP Phase-I ignition test lead to results very close to the experimental ones concerning the evolution of the ignition front. Specific hypotheses or code models were necessary for these calculations:

- an additional flow path reduction of $30-40 \%$ has been modeled with an increase of the volume of the oxides formed during the cladding oxidation, in order to follow the sharp flow rate reduction at ignition,

- a new radiation model was implemented to account for the axial radiative flux, in order to reduce the maximum temperature in the bundle and to fit the downward propagation of the ignition front,

- a new model to account for chemical reactions between nitrogen and the $\mathrm{Zr}(\mathrm{O})$ layer of the cladding was added, leading to a significant additional heat source to sustain the ignition front.

Still some experimental details cannot be calculated, illustrating some incomplete modeling. The calculated temperature rates at ignition are half the value of the experimental ones, and the main cause is due to the axial radiative HT model, which is nevertheless necessary to avoid too high peak temperature cladding. There is also a temperature mismatch above the level of the first ignition event. Experimental temperatures remain below $1100^{\circ} \mathrm{C}$, while comput- ed temperatures reach $1400^{\circ} \mathrm{C}$, following the temperature evolution of the lower levels.

\subsection{SFP-Phase II post-test calculations}

The main starting point to begin with this calculation is to keep the whole set of previous code options used for the best estimate calculation of the SFP Phase I.

Main changes are related to the modeling of a new geometry and to the boundary conditions of the central cell with another adjacent unheated cell, which is only heated asymmetrically by its side in contact with the central cell. Due to symmetry considerations, we model only $1 / 8^{\text {th }}$ of the whole facility, with $1 / 8^{\text {th }}$ of the central cell (similar to the SFP-I one), and one half of the adjacent cell, modeled with $4 \times 7$ meshes, including weighed representative rods (Fig. 14).

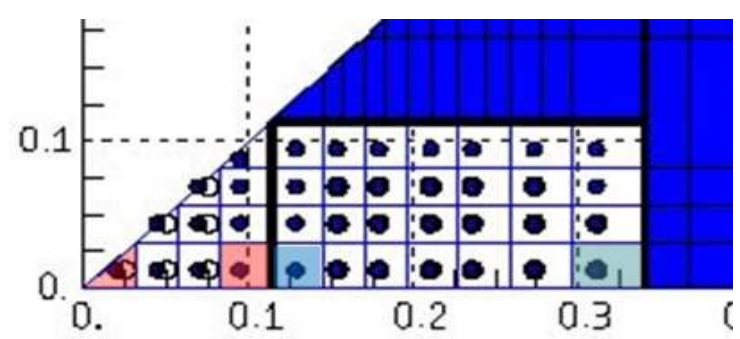

Fig. 14 SFP-II meshing 1/8 modeled

\subsubsection{First calculation results}

Some parametric adjustments related to this specific geometry were nevertheless necessary to reproduce more closely the main experimental features, before searching for a best estimate calculation.

Singular pressure losses: because of different inner dimensions of both cells, a new series of calculations has been done to adjust the value of the singular pressure loss coefficients. Their values have been increased by $\sim 30 \%$ to match the experimental flow rates in both cells, prior and after ignition (Fig. 15). This result supports the working hypothesis of an increased volume of the oxides. Nevertheless, additional flow blockage did happen during the test. If no specific hypothesis is used in the calculation to take this blockage into account, the sharp decrease is not reproduced. As an illustration of this fact, the many US-NRC calculations done with MELCOR (Durbin 2016b), using only parametric values for minor and major pressure drop coefficients, did not reproduce the sharp decrease of the flow rates after ignition.

The flow rate evolution is also related to some specific timing of events in the test. The first major disturbance in 


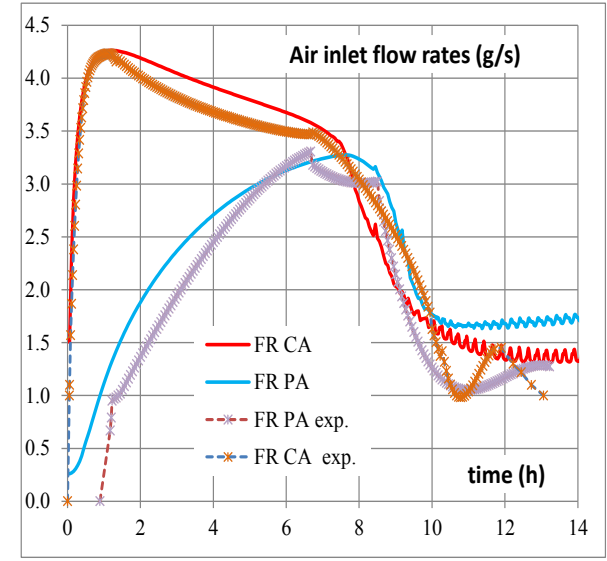

Fig. 15 SFP-II Flow rates evolution

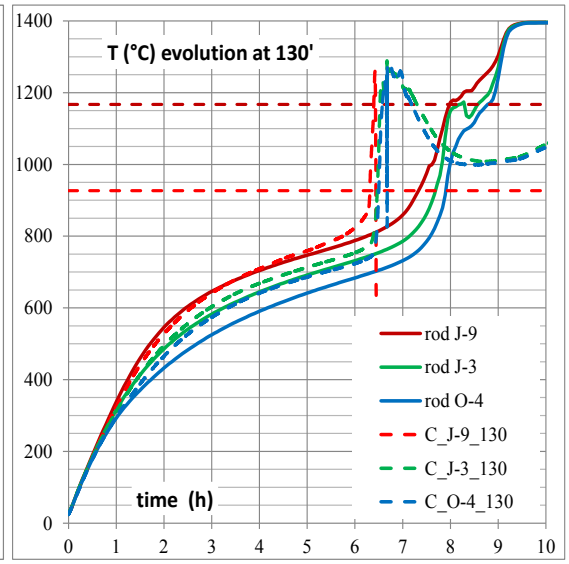

Fig. 16 SFP-II Temperature at ignition level

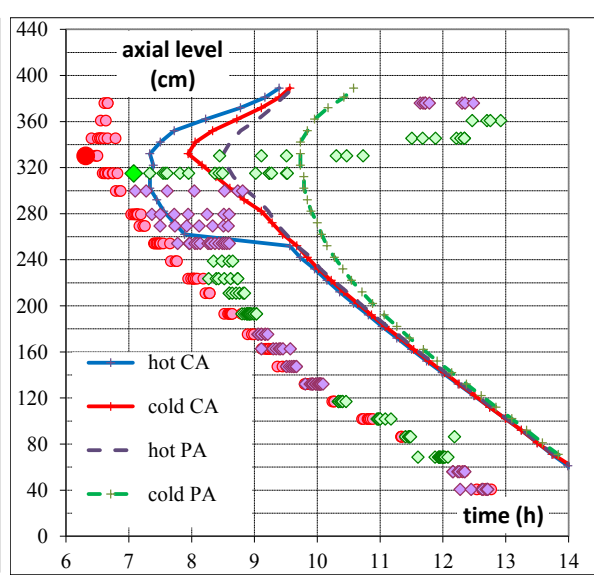

Fig. 17 SFP-II Evolution of the ignition front the flow occurred at 6.7 hours ( $24000 \mathrm{~s})$, corresponding to the loss of electrical power in the central assembly (to avoid any short-circuit due to degraded rods at temperature above $\sim 1167{ }^{\circ} \mathrm{C}$ ). Then a sharp decrease in the peripheral assembly flow rates was recorded after 8.7 hours $(31300 \mathrm{~s})$, indicating that the ignition front had progressed across the entire cross section of the peripheral assemblies. These events, linked to the axi-radial propagation of zirconium fire in the cells, have been more or less correctly reproduced in our calculations when adjusting parameters for the post-ignition phase of the test, thus leading to correct flow rates calculations.

Axial radiation HT corrective factor: another parametric adjustment was necessary to get an adapted correction for the redistribution of axial radiation. In the Phase-I of the series, which was a quasi-adiabatic test, $75 \%$ of the calculated axial radiation heat correction was applied. This correction has been reduced to $40 \%$ for the Phase-II, in order to increase the temperature rate at the ignition level which was far too low due to the less insulated boundary condition of the Central assembly (CA). As many parameters are also involved in the determination of the thermal evolution, we chose to adjust the axial corrective factor in order to fit the experimental downward velocity of the ignition front, even if the first ignition event was not correctly calculated.

Let's come to the detailed results of the first calculation.

First ignition event: with these two main modifications, the first ignition event in the CA was calculated at $7.28 \mathrm{~h}$ and $3.12 \mathrm{~m}$, one hour after the experimental timing $(6.31 \mathrm{~h}$ and $3.3 \mathrm{~m}$.). Looking at the evolution of temperatures at the ignition level (Fig. 16), we can see that the cal- culated rod temperatures follow closely the experimental ones up to $700-800^{\circ} \mathrm{C}$, and remain slightly lower after (by $20^{\circ} \mathrm{C}$ at $800^{\circ} \mathrm{C}$ ). The one-hour-delay for the ignition event is mainly due to a much lower value of the temperature increase rates calculated during the runaway. Experimental temperature rates at ignition level are higher than $80^{\circ} \mathrm{C} / \mathrm{min}$, while the calculated ones are not higher than $10^{\circ} \mathrm{C} / \mathrm{min}$. Contrary to what happened for SFP-I, the chosen corrective factor for the axial radiative flux is only $40 \%$, correction at which there is a low effect on the temperature rates, but a larger one on the peak cladding temperature value, with a direct link with the front velocity.

In the experimental test report (Durbin 2016b), sensitivity studies on pre-to-post-breakaway oxidation kinetics have shown that the results are highly sensitive to both oxidation kinetics and the transition to breakaway. MELCOR results concerning the predicted time of ignition could vary up to several hours. It was also highlighted that the addition of significant energy from the oxidation of the zirconium by nitrogen, coupled with the substantial reduction of convective energy exiting the assembly, likely led to greater temperature rates during the primary oxidation period, greater than can be predicted by oxidation with oxygen alone.

In order to improve this first calculation, we checked these sensitivity studies on temperature rates with DRACCAR. The additional heat due to the zircaloy nitriding modeling did not change much the rates. Using the MOZART kinetics, we performed however some parametric calculations with the coefficients initiating the breakaway. The different results lead only to small shifts for the timing of the first ignition, lower than one hour. However, a best calculation was obtained with an increase of the standard coefficients by $20 \%$. The suspected substantial reduction of 
convective energy exiting the assembly is probably linked to specific hydraulics of the entire assembly. This part will be studied in the paragraph related the best estimate calculation.

Axi-radial propagation of the front: the axi-radial propagation of the ignition fronts in the cells is illustrated in Fig. 17. In that figure, experimental ignition timings for both the central assembly and the PA (East and West cells) are compared with the corresponding code results, based on the locations of the hot and cold rods of the central and peripheral assemblies highlighted in Fig. 14.

At the ten-hour time scale of the Fig. 17, the propagation of the experimental front across the cells is limited to the PA, until the front behaves like one front for all cells below two meters. The DRACCAR first results reproduce correctly the moment where the front is one for all cells, but with a time delay of about 2.5 hours. This shift comes from an incorrect calculation of both the onset of the ignition for the central rods (blue curve), and also of the radial propagation across the CA (outer rods (red curve)).

To get a better understanding of how the ignition front propagates radially in the central cell, we looked into the detailed code sequence to build the following scenario:

- at first, there is a strong heating of the central rods due to oxidation reactions. Shortly after the ignition temperature being reached, the power from oxidation (which is largely above the residual one) drops to zero due to starvation of oxygen in the channel,

- the lack of oxygen starts the nitriding reactions, but with a small additional heating because the temperature of the rods is still below $1100^{\circ} \mathrm{C}$. However, this additional heating from the nitriding reactions helps the next outer peripheral rods to reach ignition, until the rods close to the cell ignite.

In this scenario, the oxidation of the cladding is the main provider of energy for the radial propagation of the front, but with the necessary help of additional heating from the nitriding reactions in order to reduce the timing for the radial propagation. The correct sequence of events is much dependent on the distribution of air in the channel (via the cross flow modeling) for the establishment of starvation conditions, dependent on the nitriding modeling, and on the radial temperature gradient within the bundle, for the outer rods to reach the ignition temperature (or not).

\subsubsection{Best calculations for SFP-III test}

Coming back to the code results for the axi-radial propagation of the temperature front, the 2.5 hours' time delay in the calculations is a combination of the initial delay of one hour for the first ignition event, with the additional timing for the zircaloy fire to propagate within the central assembly. The search for a best calculation will aim at reducing these delays as much as possible.

a) Increasing the hot rod temperature at the ignition level: in the code modeling, the cell wall of the CA exchanges heat directly with the adjacent wall of the peripheral assembly (PA), the heat being then propagated to the three other walls of the adjacent cell by azimuthal conduction.

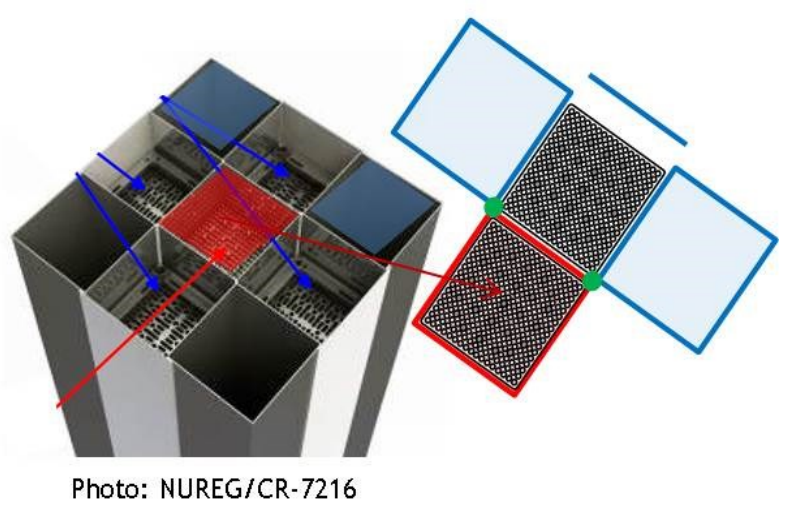

Fig. 18 SFP-II Cells arrangement

A close-up view at the cells arrangement (Fig. 18) may indicate that instead of a rack composed of nine cells, we could have a five-cells rack, with four empty peripheral cells being clipped to the CA cell by its four corners (with some different clipping material), the peripheral assemblies being inserted in the middle and empty space. If so, this could reduce the azimuthal heat conduction of the walls surrounding the PA, so reducing the heat losses of the CA.

In the DRACCAR modeling, it is possible to stop the azimuthal heat conduction in the cell walls of the PA. After running such a conservative calculation, the first ignition event happened at $6.21 \mathrm{~h}$, just before the experimental one. The following evolutions of the ignition fronts are plotted in Fig. 19.

The results look much better as there is no more time shift between the code results and the experimental fronts below $2.5 \mathrm{~m}$. Still, the onset of ignition in the upper part of the bundle is not correct, with an advance timing of ignition for the central rods (blue line) and with still a too large time delay for the front to propagate within the CA.

b) Reducing the zirconium fire propagation in the central cell: if we look at the radial propagation of the experimental 
front in the CA, we see that there is a delay of about $15 \mathrm{~min}$ for the front to propagate in the CA, and that the initial onehour delay always calculated with DRACCAR is too large.

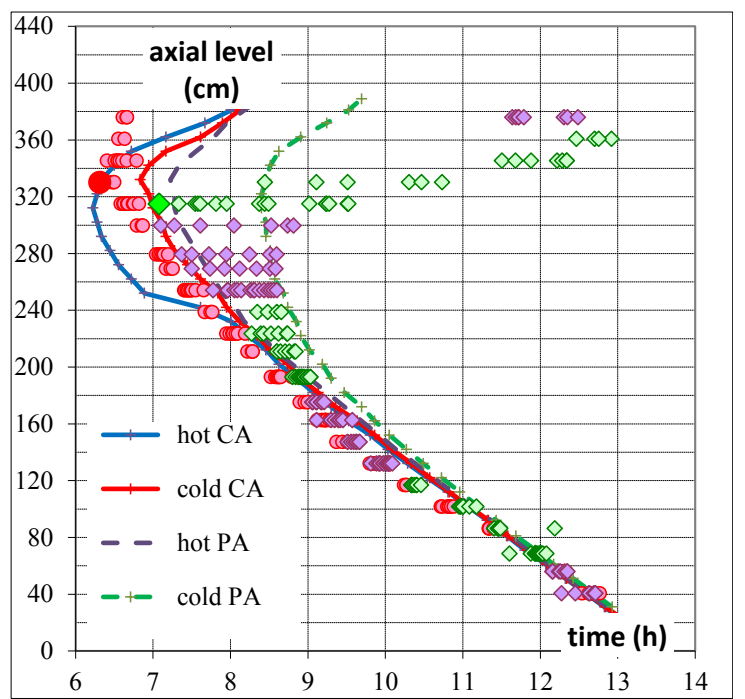

Fig. 19 SFP-II evolution of the ignition front with no azimuthal conduction

This (obviously) can be due to some incorrect radiation modeling to be improved, but looking at the sequence of events for the front for the radial propagation across the $\mathrm{CA}$ (previously described) there is still two possibilities to get improved results.

First, the early stop of the cladding oxidation due to the local starvation of oxygen is linked to the flow distribution in the meshes which cannot be experimentally checked. Another calculation with a modified flow distribution within the meshes could be done using the 'no cross-flow' option. This will be tested in $\S b .2$, but based on a different initial motivation which will be to modify the convective heat exchanges near the bottom of the bundle.
Another possible effect for increasing the radial propagation of the ignition front is linked to the stopping of the electrical power in the test. The power is stopped as soon as a temperature of $1167^{\circ} \mathrm{C}$ has been reached in the bundle. The temperature difference between the ignition temperature and the power-stopping temperature $\left(240^{\circ} \mathrm{C}\right)$ is in the same range than the radial temperature gradient in the CA. Within the DRACCAR modeling, this means that when the power is stopped, the oxidation front has not yet reached the periphery of the bundle. The outer rods which are no longer heated will cool down, and it will take an extra time delay for the front to reach the rods close to the cell.

This is illustrated in Fig. 20, in which the central rod temperatures (plain line) are plotted together with the outer ones (at the same level (dashed line)) at ignition level and at the level of the sharp time shift of the calculated ignition front at $2.5 \mathrm{~m}$. We can see that at $2.5 \mathrm{~m}$, the increase of the temperature of the central rod is stopped with the power before reaching ignition, leading to a slow decrease of its temperature. After one hour, due to the fact that the front is reaching that level, a second temperature increase happens for all the rods of the level, with ignition events detected with only a small time delay for all the rods.

b.1) Enhancing nitriding: because nitriding reactions give additional heating for the front to propagate radially (in the way it is modeled), we ran other calculations increasing the coefficient of the kinetics by $30 \%$ in order to enhance the propagation. Code results show that the ignition front for the central rods remains almost unchanged in the upper part, with only a slight advance of the front (about twenty minutes) below the level $2.5 \mathrm{~m}$. This is an indication that the ignition of the central rods is mostly triggered by oxidation reactions. The evolution of the outer rods didn't change

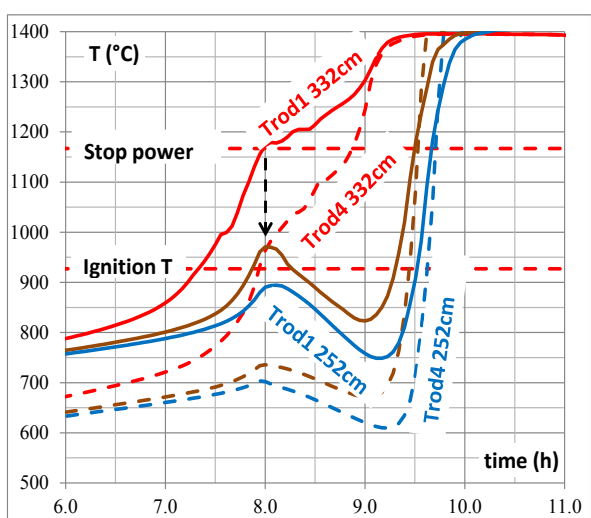

Fig. 20 SFP-II Rod temperatures from $3.32 \mathrm{~m}$ to $2.52 \mathrm{~m}$

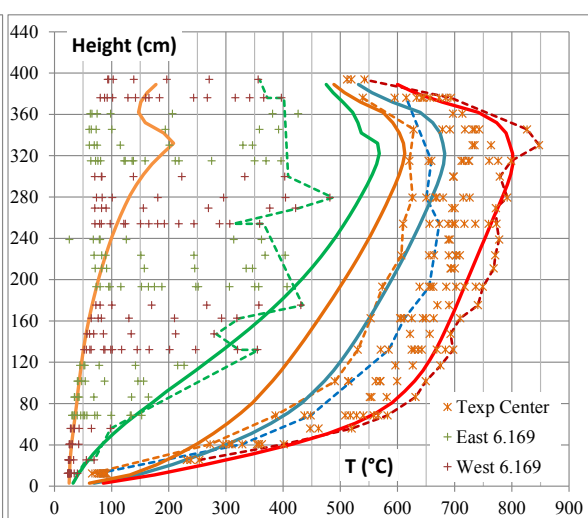

Fig. 21 SFP-II Axial temperature profile before ignition

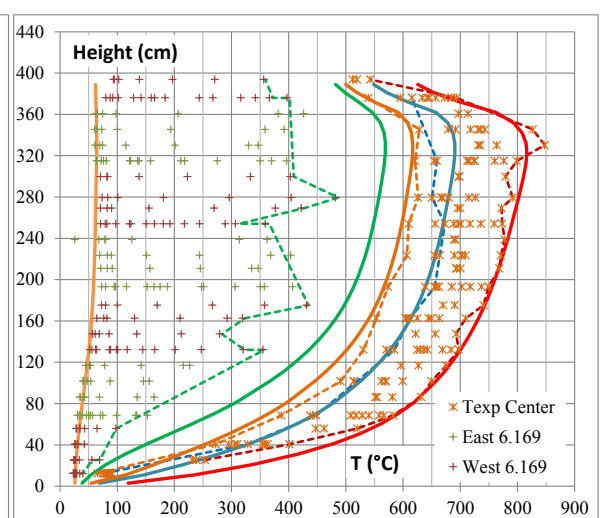

Fig. 22 SFP-II Axial temperature profile before ignition no cross flows 
much as well.

b.2) Reducing the radial temperature gradient: looking at the evolution of the temperatures at the ignition level (Fig. 16), we can see that the calculated temperature gradient across the bundle is at least $50^{\circ} \mathrm{C}$ larger than in the test. In order to check the temperatures at various levels, the thermal state of the bundle prior to ignition has been plotted in Fig. 21. In that Fig. we have plotted the experimental temperatures at $6.17 \mathrm{~h}$, and those of the corresponding rods in DRACCAR. The dashed lines highlight experimental temperatures for the central cell (central rod, rods close to the cell and rods in the corner) and for the peripheral ones (rods close to the cell). It is seen that the calculated radial temperature gradient in the $\mathrm{CA}$ are too high (by $50{ }^{\circ} \mathrm{C}-100{ }^{\circ} \mathrm{C}$ ), but mainly in the lower part of the bundle, and not only focused at the ignition level as indicated by Fig. 16

Looking at the temperatures in the peripheral cell, they are also much too high at the hot spot location.

Flow rates in the $\mathrm{CA}$ : at $6.17 \mathrm{~h}$ (Fig. 21) there is only a small additional heating from the cladding oxidation, and the main difference with the experimental results comes from the coldest rods of the calculation (close to the cell wall) which are too cold. For these rods, convective heat exchanges are dominant on the whole height of the bundle, so highlighting the importance of the mass flow rates in that calculation.

In the DRACCAR modeling, cross flows are allowed between meshes, leading to convective loops within the bundle, (some channels feeding others), and leading even to recirculating loop inside the peripheral cell, thus increasing the flow rates of the meshes close to the cell wall to the detriment of the central meshes. Because there is no readily validation of these processes, we ran a calculation without cross flows between meshes. The thermal state (at $6.17 \mathrm{~h}$ ) in the bundle resulting from such a hypothesis is depicted in Fig. 22. As long as the CA is concerned, the results for the temperature profiles are much better, with a reduction of the radial temperature gradient toward the experimental ones. The temperatures of the hot rods remain nearly unchanged, but those of the cold ones have been increased by about $100^{\circ} \mathrm{C}$.

These good results are mainly due to a lowering (by about $15-20 \%$ ) of the mass flow rates in the channels near the cell. The main effect of the cross flow modeling along the bundle height is to increase the flow rates of the meshes close to the cell wall to the detriment of the inner meshes, leading to overcooled rods close to the cell wall.

Heat transfers to the PA: concerning the peripheral cell and the temperatures of the hot rods near the cell wall, the results are not improved by blocking cross flows. The temperature profile of the hot rods follows more closely that of the cell from the bottom for the same reason than for the $\mathrm{CA}$ : the rods close to the cell wall being much less cooled by the flow rates. However, some improvements are seen for the temperatures of the cold rods (at the opposite side of the PA cell) which do not exhibit a $\sim 200^{\circ} \mathrm{C}$ temperature peak at $3.3 \mathrm{~m}$. This peak was due to the existence of a recirculating loop for the flow rates when cross flows were calculated.

These results indicate that prior to any ignition, heat transfers to the peripheral cell are not correctly estimated, even in modeling the exact geometry. But as long as we remain focused on the ignition events, that non-exact thermal state of the PA is not important because the ignition of its rods is triggered by those of the CA.

Post ignition results: the resulting evolution of the ignition fronts is illustrated Fig. 23. Because of the 'non cross flow' hypothesis, temperature of the outer rods of the CA is higher, increasing de facto the temperature of the central rods and leading to a first ignition at $6.95 \mathrm{~h}$ and at $3.22 \mathrm{~m}$ (at about twenty minutes before the first calculation with cross flows). Looking at the overall evolution of the ignition fronts, the results look much better with a smooth evolution of the fronts in the CA. The first ignition event is still delayed by 35 minutes in comparison to the experiment, and the ignition in the peripheral assembly is also delayed compared to the test.

Coming back to the first envisaged possibility ( $\$$ b) to reduce the time of the zirconium fire propagation in the CA by enhancing the local oxygen composition, the calculation without cross flows brings a different scenario. Using or not the cross flow modeling does not change much the local oxygen availability, and so the timing for the radial progression of the front remains nearly unchanged. The main difference comes from a small but constant oxygen availability at $3.3 \mathrm{~m}$, due to convective loops formed with the cross flow modeling, and leading to a peak cladding temperature in the bundle which remains at $3.3 \mathrm{~m}$ a much longer time than in the case of not using the cross flow modeling. 
What is best: at first sight, the hypothesis of deteriorated azimuthal heat conduction in the PA cell leads to an evolution of the ignition front close to the experimental one, with a short ignition time delay between the cells.

However, neither the thermal state of the CA prior to ignition is correct, nor is the radial propagation of the initial ignition front in the $\mathrm{CA}$, which takes much time, due to a peak cladding temperature which remains at $3.3 \mathrm{~m}$. Finally, the hypothesis of a five-cell rack structure is still an ad-hoc working hypothesis.

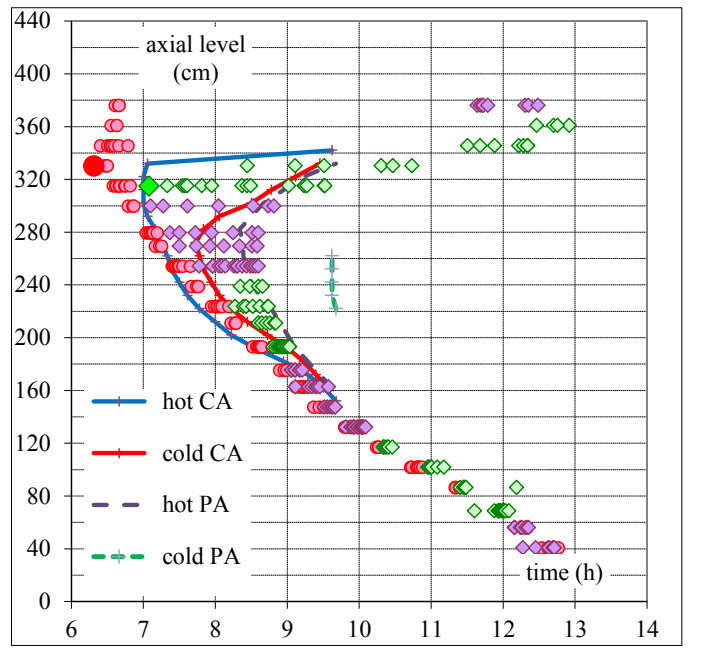

Fig. 23 SFP- II evolution of the ignition front with no cross flows

The other hypothesis with a modified distribution of the flow rates leads to an accurate thermal state of the CA prior to ignition, to a correct development of the ignition front in the CA below the first ignition level, but still with a delay of $\sim 40$ minutes for the ignition onset. Above that level, the incorrect results could be related to the simple nitriding modeling. A calculation done with the additional hypothesis of a deteriorated azimuthal heat conduction (to gain the 40 ' delay) lead to incorrect results with a front in advance by one hour.

There is also an incorrect timing for the ignition front of the $\mathrm{PA}$, which is delayed by 35 minutes as the ignition front of the CA reaches the cell wall. As previously explained, this incorrect result could be due to a wrong heat transfer calculation between cells, and should be improved with modifications of the corresponding radiative heat transfers modeling in the code.

There is another experimental clue which goes in favor of the incorrect flow rates hypothesis of the standard calculation. In the experiment, the rods of the PA located at (and above) the first ignition level reached the ignition temperature late in the test, after eleven hours when the front is close to the bottom of the assembly. This is an indication that the temperatures of the CA at those upper levels, after having reached peak temperatures due to cladding oxidation, rapidly cool down due to starved conditions, bringing together the PA temperatures to cool down before reaching the ignition threshold. These starved conditions above $3.3 \mathrm{~m}$ are not calculated at all with the standard cross flows option allowing convective loops, whereas starved conditions appear when avoiding the cross flows.

\subsubsection{Summary of the Phase-III calculations}

To resume DRACCAR calculations of the second ignition test of the Sandia Fuel Project, we have seen that a direct use of the best code options obtained from the SFP-I calculations (with an optimization of the pressure drop coefficients and of the amount of the axial radiative correction), led to low temperatures in the bundle, incorrect calculations of the ignition fronts in the upper levels, and to a 2.5 hours' time delay of the common front below $2.5 \mathrm{~m}$. Different hypotheses have been tested with success to improve code results, but without totally matching the experimental ones. These facts are an indication that the Phase-II test conditions are much different than those of the Phase-I, at least before the onset of a common ignition front in the five cells.

A temperature gradient, radially established in the hot CA, greater than that the one in the SFP-Phase-I test, leads to code results being much sensitive to local temperature thresholds and gas starvation conditions, and to flow rates distribution within the bundle. Within the electrically heated CA, the flow rates are mainly driven by the whole set of rods and should be mostly axially oriented, explaining why the "no cross flow" chosen option gives much better results.

For the cold PA, the flow distribution is more complex due to the lateral heating. In our calculations, the influence of the grids was only limited to an overall singular pressure drop effect, allowing an exact calculation of total flow rates in the bundles, but not allowing the detailed distribution of it, mostly if non-experimentally checked convective loops are calculated.

\section{Conclusion}

The OECD/NEA Sandia Fuel Project conducted at Sandia National Laboratories during three years (from July 2009 to February 2013) has provided a large set of available experimental data associated with Spent Fuel Pool complete Loss 
of Coolant accident. The two series of test of that program were related to the study of zirconium fire due to air ingress in a bundle with two different boundary conditions, from a most adiabatic one to a less insulated boundary conditions, leading to small or large radial temperature gradients in the bundle.

This set of experimental data available for code validation can be separated in three main parts of interest for code validation:

i) A first accurate hydraulic data set to validate hydraulic models in codes,

ii) An experimental timing for the first ignition event at which the temperature in the bundle reaches the ignition temperature at $927^{\circ} \mathrm{C}$. This part allows a checking of the oxidation laws and the model of breakaway in the code,

iii) And finally a set of accurate timings for the axial and radial propagation of the zirconium fire in the bundles, to test the code capabilities to predict rods degradation in the case of air ingress accidents.

For IRSN, which participated as an international partner to that program, the non-axi-symetric geometry of the second part of the project has been a decisive argument to use the DRACCAR code for post-test calculations. In order to illustrate the good consistency of the code modeling for calculating air ingress accidents for two different sets of geometry, the following process for code calculation has been applied: the first (and most adiabatic) test of the program has been calculated by developing new modelings and by adjusting code parameters. Then the second (and less insulated) test has been done using basically the same code options.

DRACCAR calculations of the first ignition test of the SFP series (at $5 \mathrm{~kW}$ ) were very successful and challenging, leading to several code improvements. After adjusting the code input pressure drops during the heat up phase, it was necessary to take into account an increase of the volume of the rods due to oxides formation. Modifications of the radiative heat transfer modeling to include corrections due to axial heat transfers in case of very high temperature gradients (above $100^{\circ} \mathrm{C} / \mathrm{cm}$ ) were necessary in order to avoid too high temperature for the rods (above $2000^{\circ} \mathrm{C}$ ) and to get the correct and experimental downward velocity of the ignition front in the bundle.

Because of experimental evidences of nitrogen consumption to produce $\mathrm{ZrN}$, a simple and parametric model of zircaloy nitriding was developed, based on experimental results obtained at KIT (Steinbrück). The use of that model in adiabatic test conditions led only to slight improvements of the propagation of the ignition front below mid bundle. The onset and the main propagation of the ignition temperature have been well captured using the MOZART kinetics (Duriez) for the cladding oxidation, and the breakaway model (Coindreau) to describe the changes of the oxidation kinetics.

DRACCAR calculations of the second ignition test of the SFP series (at $15 \mathrm{~kW}$ ) have been performed with the same code options than for the SFP-I test, with few modified input values tuned-up to the new test features. First calculations did not predict correctly the initial propagation of the zirconium fire front within the bundles. Better results have been obtained in using additional hypotheses to model a more complex experimental situation, linked to a less insulated hot central cell. Still a correct thermal state of both cells (prior or after ignition) cannot be calculated with DRACCAR, especially due to the difficulty of calculating a correct flow distribution within the bundles, and of reaching correct heat transfers between cells.

Finally, the detailed calculations presented in that paper have shown that the DRACCAR code can initiate temperature runaways and calculate propagation of zircaloy fires within various bundles submitted to air ingress situations. The calculated timings are close to the experimental ones, but looking into details, some experimental events are still difficult to reproduce. As many causes could be involved in these incorrect code results, there is still room for improvement in the work of interpretation and modeling of the SFP Phase I and II tests.

\section{References}

Adorni M. et al, 2016, "OECD/NEA Sandia Fuel Project phase I: Benchmark of the ignition testing", NED 307, 418-430.

Bascou S. et al, 2015,. "Development and validation of the multi-physics DRACCAR code". Ann. Nucl. Energy 84, 1-18.

Cardoni J., 2010,. "MELCOR Model for an Experimental 17x17 Spent Fuel PWR Assembly". Sandia Report SAND2010-8249

Chatelard P., 2016, "Main modelling features of the ASTEC V2.1 major version", Annals of Nuclear Energy 93 (2016) 83-93. 
Coindreau, O., Ederli, S., Duriez, C., 2010. Air oxidation of zircaloy-4 in the $600-1000$ C temperature range: modelling for ASTEC code application. J. Nucl. Mater. 405, 207-215.

Collins T.E., Hubbard G., 2001, "Technical Study of Spent Fuel Pool Accident Risk at Decommissioning Nuclear Power Plants", NUREG-1738.

Durbin S.G., Lindgren E.R., Goldmann A.S., 2016a, "Spent Fuel Pool Project Phase I: Pre-Ignition and Ignition Testing of a Single Commercial 17x17 Pressurized Water Reactor Spent Fuel Assembly under Complete Loss of Coolant Accident Conditions", NUREG/CR-7215.

Durbin S.G., Lindgren E.R., Humphries L., 2016b, "Spent Fuel Pool Project Phase II: Pre-Ignition and Ignition Testing of a 1x4 Commercial 17x17 Pressurized Water Reactor Spent Fuel Assemblies under Complete Loss of Coolant Accident Conditions" ", NUREG/CR7216.

Duriez, C., Dupont, T., Schmets, B., Enoch, F., 2008. Zircaloy-4 and M5 high temperature oxidation and nitriding in air. J. Nucl. Mater. 380, 30-45.

Glantz T., et al., 2017, "DRACCAR: a multi-physics code for computational analysis of multi-rod ballooning and fuel relocation during LOCA transients. Part one: General modeling description.", to be published at NED

Lasserre M., et al., "Modelling of Zircaloy-4 accelerated degradation kinetics in nitrogen-oxygen mixtures at $850{ }^{\circ} \mathrm{C}$ ", Journal of Nuclear Materials, J. Nucl. Mater. 462 (2015) 221.

Lindgren E. R., Durbin S. G., 2013a, "Characterization of Thermal-Hydraulic and Ignition Phenomena in Prototypic, Full-Length Boiling Water Reactor Spent Fuel Pool Assemblies After a Postulated Complete Loss-of-Coolant Accident", NUREG/CR-7143.

Lindgren E. R., Durbin S. G., 2013b, "Laminar Hydraulic Analysis of a Commercial Pressurized Water Reactor Fuel Assembly", NUREG/CR-7144.

M. Steinbrück, "Prototypical experiments relating to air oxidation of Zircaloy-4 at high temperatures"J. Nucl. Mater. 392 (2009) 531

Steinbrück M., 2014. High-temperature reaction of oxygen-stabilized $\alpha-\operatorname{Zr}(\mathrm{O})$ with nitrogen. J. Nucl. Mater. $447,46-55$.

Trégourès N. et al., 2010, "Reactor cooling systems assessment of the ASTEC V1.3 code in support to the French IRSN PSA-2 on the 1300MWe PWR". NED 240,1468-1486. 